\title{
A TRI-RADIATE TAPEWORM (ANOPLOCEPHALA PERFOLIATA GOEZE) FROM THE HORSE.
}

\author{
By F. J. MEGGITT, M.Sc., \\ Board of Agriculture and Fisheries Research Scholar, \\ University of Birmingham.
}

(With Plate XVIII and 2 Text-figures.)

\section{Introduction.}

WhILE fixing a number of tapeworms (Anoplocephala perfoliata Goeze) from the small intestine of the horse, I came across a small tri-radiate specimen. This abnormality has previously been described by Neumann (2), but only briefly, and without any account of the internal anatomy. It therefore seemed advisable to compile a short account of the most salient characteristics. For the material I am indebted to Dr C. L. Boulenger, Helminthologist of this Department. I have also to thank Professor L. G. Neumann for obtaining for me a copy of his paper.

The horse from which the material was obtained had died from the cumulative effects of numerous parasites. On opening the small intestine at the post-mortem, it was found to be almost entirely filled with huge masses of the tapeworms. Only a comparatively small number were taken for subsequent fixing and examination, and it was amongst this number that the tri-radiate form was found. A close examination of the remaining tapeworms would no doubt have revealed other cases. A complete biography of all poly-radiate Cestodes hitherto described is given by Foster (1).

\section{External Characters.}

The total length of the specimen was $33 \mathrm{~mm}$; its maximum width was $6 \mathrm{~mm}$., and its posterior width $3.8 \mathrm{~mm}$. The number of proglottides was approximately 100 . The shape of the scolex and proglottides 
corresponded with the description given by Neumann. The scolex was $1.7 \mathrm{~mm}$. long by $3 \mathrm{~mm}$. wide. The six suckers varied slightly in size being approximately $1.35 \mathrm{~mm}$. long by $1.1 \mathrm{~mm}$. wide: their openings had a diameter of $0.368 \mathrm{~mm}$, and their posterior lobes were $0.86 \mathrm{~mm}$. long by $0.71 \mathrm{~mm}$. wide. The length of the central proglottides was $0.63 \mathrm{~mm}$., of the posterior $0.43 \mathrm{~mm}$.

\section{Excretory System.}

The excretory system consists of longitudinal dorsal and ventral vessels, uniting in the scolex to form a definite excretory plexus. In the remainder of the strobila they extend from the neck posteriorly, one dorsal and two ventral vessels in each arm. The dorsal vessel continues practically unchanged throughout the entire course. It runs internal to the nerve and gives off a few branches which end blindly in the parenchyma. There is no trace of a commissure connecting it with any other vessels. The ventral vessels consist of two in each arm, lateral and slightly internal to the longitudinal nerve trunk. In the middle of the proglottis, each bends outwards nearly to the tip of the arm and then returns to its former position.

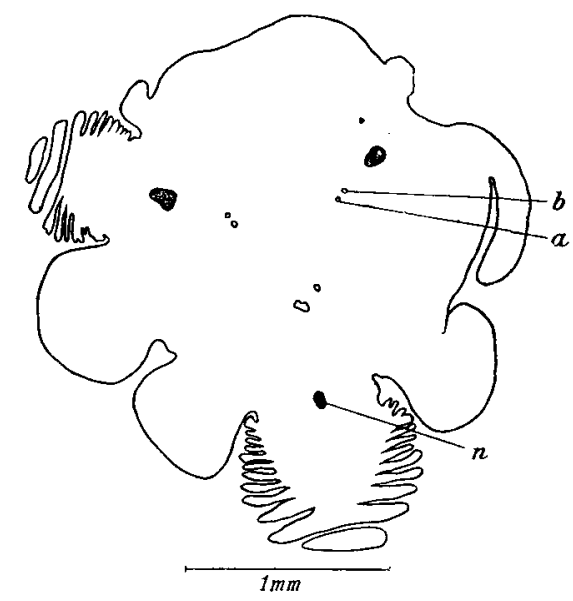

Fig. 1. Transverse section through posterior part of neck. For explanation of lettering see text.

A transverse commissure internal to the nerve connects the two vessels in the posterior part of each proglottis. In this posterior portion of the proglottis, each ventral vessel gives off one or more branches 
which run internally and fuse with one another in the centre between the three arms.

As the vessels proceed anteriorly, this definite arrangement becomes lost, until just posterior to the neck, the ventral vessels are represented only by a plexus of minute branches. As the vessels pass into the neck, the excretory plexus representing the ventral vessel merges into two large transverse vessels uniting with one another just external to the dorsal vessel. Text-figure 1 presents the typical appearance here of the excretory system in a tri-radiate Cestode. From this point, the dorsal vessel $(a)$ runs practically in a straight line into the scolex. The course of the ventral $(b)$ is more complicated (Pl. XVIII, fig. 4). Starting lateral and slightly external to the dorsal vessel, it runs half-way to the scolex, there to bend upon itself and retrace its course to a point still more lateral to the dorsal vessel and on the same side of it as before. Again it bends round upon itself, and this time goes forwards in a straight line to the scolex where it breaks up into an excretory plexus between the sucker and the outer margin of the proglottis. The branches of this plexus reunite into a single vessel $\left(b^{\prime}\right)$, which runs posteriorly, increasing in size, to a point, the same distance from the dorsal vessel as the furthermost point it reached in the first part of its course, only this time on the opposite side. From this point it again runs forward into the scolex, breaking up into an excretory plexus as before, but going to the sucker on its own side of the dorsal vessel. The posterior margins of the six suckers are thus supplied by the ventral vessels, the suckers on either side of the dorsal vessel forming a pair supplied by the corresponding ventral vessel. As before, the branches composing the plexus reunite into a large one $\left(b^{\prime \prime}\right)$ which runs posteriorly half-way through the neck and then proceeds anteriorly again, external to and closely following the course of the dorsal vessel, into the scolex. With the exception of the portion before the first bend, the whole of its course lies external to the main longitudinal nerve trunk. The appearance in this part of the scolex is shown in Text-figure 2.

The excretory system in the scolex may be divided into three parts, each occupying a third of its length. Sections through the junction of two of these parts show a regular and symmetrical arrangement, sections between the junctions show only a network of vessels. In order accurately to describe these systems it is necessary to refer to each individual vessel as the majority of them have different courses.

Each of the three ventral vessels breaks up into an excretory plexus once more. The dorsal vessels on the other hand continue without a 
plexus, two of them $(c, e)$ converging to run side by side between two suckers $(s 4, s 5)$ through the posterior third of the scolex (Fig. 2), the third (a) running by the side of another sucker $(s 2)$. In this part of the scolex three vessels appear suddenly to arise de novo. It is possible that they are formed by the collection through devious courses of the capillaries of the three ventral vessels which disappeared but this it has been found impossible to ascertain. They occupy approximately the three positions which the three vanished vessels would have occupied had they continued their courses. The new vessel between the suckers $s 5, s 6$ crosses internally to sucker $s 6$, and between suckers $s 6$ and $s 1$ divides into two $(g, h)$, each branch formed being in a similar

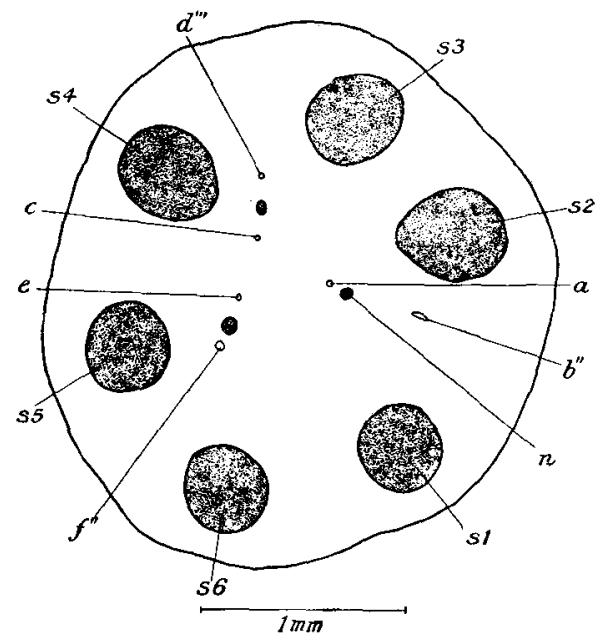

Fig. 2. Transverse section through posterior end of scolex: For explanation of lettering see text.

position to the two just mentioned $(c, e)$. A further branch communicates with the new vessel appearing between suckers $s 2$ and $s 3$. This new vessel similarly crosses sucker $s 3$, but, instead of dividing into two, runs anteriorly, the other vessel of the pair being formed by the dorsal vessel $(a)$ previously mentioned. At the posterior two-thirds of the scolex a section has the appearance shown in Fig. 2. The excretory system then consists essentially of six vessels $\left(a, d^{\prime \prime \prime}, c, e, g, h\right)$ arranged in three pairs, each pair running side by side between two suckers, slightly to one side of the main excretory course in the neck. Of these six, three $(a, c, e)$ are continuations of the dorsal vessels, the other three $\left(d^{\prime \prime \prime}, g, h\right)$ probable continuations of the ventral. 
Through the middle third of the scolex the courses of these six vessels are similar. Each runs directly anteriorly half-way along the length of its corresponding sucker and then turns back upon itself at an exceedingly acute angle to run posteriorly and externally as far as the point from which it started. Here it bends anteriorly again and runs between the sucker and the external limit of the scolex, slightly anteriorly to the farthest point it reached before. Arrived there it repeats its first acute-angled bend and proceeds anteriorly again, almost in a straight line with its course before the loops; often the two are connected by small capillaries. During its whole course minute branches are given off to the sucker, and others establish communication between the parallel portions. In the anterior third of the scolex the excretory system shows no definite arrangement, it forms an immense and intricate plexus (Fig. 5, only the larger branches are shown) the branches of which anastomose with one another and sub-divide to such an extent as to render analysis impossible.

The two vessels of each pair are first united by a transverse commissure (t.c.) each afterwards splitting up into one or more smaller vessels which combining with similar branches from the other pairs form the plexus. The labyrinth formed by one pair of excretory vessels tends to remain separate from that formed by another pair, and only communicates with it by large and definite vessels. Such communications (l.c.) are usually three on each side, but their position varies irregularly.

\section{Nervous System.}

The nervous system consists of three longitudinal nerve trunks running the whole length of the body. In the scolex they converge and at the posterior level of the suckers fuse to form a central mass. From this six nerves are sent out, one to each sucker. Numerous other branches are also given off. Owing to having only one series of sections and the consequent necessity of using a general stain, it was found impossible to follow out the nervous system with any clearness beyond this point.

\section{Genital Organs.}

The genital organs may be divided into two groups. The first occurs in the space formed by the junction of the three arms, with the female genital organs lying near the external parenchyma at the junction of arms 2 and 3 , and the male organs occupying approximately the centre of the space. The occurrence of this group is very spasmodic, 
not corresponding to the external segmentation but occurring much more frequently. The arrangement of their ducts is irregular in the extreme. The genital organs of the second group lie in arm 1 and in their occurrence correspond with the external segmentation. The courses of their ducts are quite normal and the general arrangement agrees very well with that described for this species. The male and female ducts open to the exterior in the normal manner.

In young segments the three arms are all parenchymatous with no spaces, the genital organs being embedded in the parenchyma. More posteriorly this begins to be less compact and a space forms at the point of intersection of three lines drawn down the centre of each arm parallel to its sides. This space increases in diameter until it becomes approximately circular, with the above-mentioned point of intersection for its centre, and occupies almost the whole of the space formed by the junction of the three arms (Fig. 7, c.sp.). In this space lie the chief male genital ducts of the first group, cirrus, vesiculae seminalae, cirruspouch, etc., supported by thin strands of tissue which fix them to the sides. Posteriorly this space is practically continuous through the remainder of the strobila and forms a ready means of communication between the different proglottides. Into it, close together, open the male and female genital ducts. In the anterior part of the strobila where there is no central space, its place being occupied by a compact block of parenchyma, these genital ducts have no outlet and end blindly in the parenchyma: it is not until this space is developed that the ducts become functional.

It is obvious that for the genital organs of the first group there can be no cross-fertilisation, self-fertilisation must be the natural order of things. The male and female ducts opening side by side into the central space would make it easy for the cirrus to fertilise the vagina of the same proglottis. This need not necessarily be the case though. The central space passing through the matrix segments would afford a ready means of communication between the different proglottides.

Spermatozoa shed into this passage would wander through it and enter any one of several vaginae: there could therefore be cross-fertilisation between two proglottides. It is certain that fertilisation actually occurs. Both male and female organs are well-developed, producing mature and apparently normal ova and spermatozoa, and mature and developing eggs are present in the uterus. 


\section{Male Organs.}

The male organs of the first group present a peculiarity so far not recorded. They are usually arranged in pairs, each pair having a common opening into the central space. The vesicula seminalis and vas deferens of the more anterior of the pair run posteriorly and those of the more posterior run anteriorly, the cirri of both opening into a common duct which then opens into the central space. This arrangement is occasionally varied by segments in which the male ducts do not join either those of the preceding nor those of the succeding segment: in that case the ducts are always incomplete, a vesicula seminalis being present, but no cirrus and no opening.

The common duct (Fig. 6, c.d.) of each pair of male genital organs is a short tube, enlarged at its outer end into a small sinus (g.s.). From this it runs towards arm 2 , and after a short course reaches the point where the two cirri open into it, there ending blindly. The arrangement of the other ducts in each of the pair is the same, if allowance be made for the difference caused by one being situated anteriorly and one posteriorly. The more anterior cirrus (Fig. 3) runs slightly anteriorly and towards the junction of arms 1 and 2 until it reaches the lateral limit of the central space. Here it bends round and opens into a large vesicula seminalis (a.v.s.). This runs posteriorly and retraces the course of the cirrus nearly to the lateral limit between arms 1 and 3 of the central space where it contracts to an exceedingly narrow tube passing through a thick highly muscular cylindrical mass (c.s.) $0 \cdot 15 \mathrm{~mm}$. in transverse diameter. The other cirrus meanwhile has run in a similar manner first posteriorly and then anteriorly, opening into a vesicula seminalis (p.v.s.) which also opens into this muscular mass.

At the posterior and anterior limits respectively in this organ the two ducts often fuse. This is the last point where they come into contact with each other. From here, one runs anteriorly and one posteriorly for some distance through this muscular organ, finally to open into a second vesicula seminalis $\left(a .^{\prime} v .^{\prime} s .^{\prime}, p^{\prime} v .^{\prime} s .{ }^{\prime}\right)$. From a comparison of transverse sections of the tri-radiate Cestode with similar sections of a normal one, I am inclined to think that the muscular organ (c.s.) just referred to is the extreme inner end of the cirrus sac. It is however much thicker and much more muscular than in normal specimens and usually is not continued round the cirrus and first vesicula seminalis. Sometimes the two latter are surrounded by a membrane but usually they are free. On the other hand, in normal specimens there 
is an internal vesicula seminalis in the cirrus sac separated by a short narrow duct from an external vesicula seminalis outside the cirrus sac, the part of the cirrus sac through which this duct passes being much thickened. This corresponds with what occurs in the tri-radiate Cestode. On that hypothesis, the vesicula seminalis (a.v.s., p.v.s.) first mentioned is the internal one inside the cirrus sac, the second (a.'v.'s.', $\left.p .^{\prime} v .^{\prime} s .^{\prime}\right)$ is the external one outside the cirrus sac, and the muscular organ (c.s.) is the only persistent, although abnormal, part of the cirrus sac through which the connecting duct between the two vesiculae seminalae passes.

The course of the external vesicula seminalis (Fig. 3, a.'v.'s.', Fig. 6, p.'v.'s.') is very irregular. It always lies at the base of arm 1 or arm 3, and, after a more or less convoluted course, narrows to form a vas deferens (Fig. 3, a.v.d.), dividing and sub-dividing into numerous minute vasa efferentia. These intertwine with each other considerably, but finally lead to the small spherical testes. The latter lie in three separate groups in the parenchyma surrounding the central space, one group at the base of each of the three arms, extending along as far as, or occasionally beyond, the dorsal excretory vessel. The groups are not distinct from each other, but are only local aggregations upon a continuous chain of testes surrounding the central space on three sides, the fourth and free side being that facing the ovary.

The testes appear very quickly after the scolex and in quite young segments are well-developed: in those segments, vasa efferentia and vas deferens are also present. In older segments the testes commence to degenerate and in proportion as the male ducts develop tend to disappear. The spermatozoa are formed and are ejected into the vasa efferentia before the male ducts have completed their development, so that in young proglottides with testes the vas deferens is empty, but in older segments without testes it is filled with spermatozoa. As the male ducts are completed towards the central space, the spermatozoa move along them as far as the internal vesicula seminalis where they are usually stored. The development of the outer portions of the male ducts is at first apparently quite normal, each set being quite distinct from its neighbour: as development proceeds however, each set approaches closer to its fellow, fusion eventually taking place when the internal.vesicula seminalis is filled with spermatozoa ready for copulation. The common opening is then formed. This development accounts for the peculiarity before mentioned of the male ducts of a proglottis being always incomplete, possessing neither cirrus nor opening, when 
they do not fuse with those of a neighbouring segment. No fusion of ducts having taken place, the development is arrested at that stage and no opening not cirrus can be developed.

\section{Female Organs.}

The female organs of the second group present no peculiarities worth mentioning. In the first group the ovary (Figs. 7 and $8, o v$.) has the form of an arc with a plane side following the margin of the proglottis, the other side sending out at right angles numerous lobes which stretch half-way across the arm. The lateral ends of the ovary are at the limit of the inner two-thirds of the length of the arm, i.e. from arm 2 to arm 3 the ovary occupies exactly the inner third, following the margin. Its plane border is exceptionally close to the musculature, touching it in some places. At its exact mid-point on the lobed (i.e. inner) side is the oöclapt $(o \bar{o} c$. $)$. On either side of this, for a short distance, the ovary is only a simple unlobed band, the lobes only occurring lateral to all female ducts and glands with the exception of the uterus. In structure, the ovary corresponds to the usual Anoplocephala type.

The vitelline gland (y.g.) is two-lobed, lying internal and slightly posterior to the ovary. Externally it nearly touches the band part of the ovary, laterally it stretches as far as the lobes, filling the break in their line. Posteriorly its two lobes communicate by a narrow bridge from which proceeds the vitelline duct $(y . d$.$) . In the hollow of the$ " $U$ " thus formed lie the oviduct and shell-gland.

The receptaculum seminis (r.s.) is rather variable in position. Usually it lies slightly towards the arm 3 side of the exact centre, with its inner end pointing towards the ovary through the U-shaped hollow of the vitelline gland and its outer end to the corresponding position at the junction of arms 1 and 3 . Occasionally. it swings round upon its inner (oviducal) end until its vaginal end points towards the corresponding position at the junction of arms 1 and 2. In shape it is rather elongated and slightly bent, with the concavity directed towards the arm 3 side of the ovary.

The shell-gland (sh.gl.) has the usual shape, is rather compact and surrounds a small oötype. It is usually on the arm 2 side of the receptaculum seminis, near and anterior to its oviducal end, but it may also be on the arm 3 side. This variability bears no relation to that of the receptaculum seminis. The shell-gland is partly enclosed between the two lobes of the vitelline gland. 
The courses taken by the female ducts are irregular in the extreme. A typical course and arrangement can be distinguished, but this is liable to almost any variation. The oviduct (ovd.) joining the ovary and receptaculum seminis runs straight from the inner end of the latter towards the former: after crossing the vitelline bridge it bends towards arm 2, then runs for a short distance anteriorly or posteriorly and bends back again to open into the ovary through a small but pronounced oöclapt (oöc.). The part of the oviduct (ovd.') leading to the shell-gland separates from that leading to the ovary at any point before the vitelline bridge. It normally bends towards arm 2 and, after several variable curves, opens into the oötype where it receives the vitelline duct $(y . d$.$) .$ In one dubious case, the vitelline duct apparently opened into the oviduct after it had left the oötype. After leaving the oötype, the oviduct runs towards the middle point of the junction of arms 1 and 2 for a short distance, and then curves round to run in the opposite direction close to the ovarian side of the receptaculum seminis. It finally turns in the direction of the ovary and opens into the uterus $(u t$.$) . This is a rather$ narrow, little-branched tube extending nearly to the dorsal excretory vessels of arms 2 and 3, following the outline of the ovary.

In its opening to the central space, the receptaculum seminis is exceedingly peculiar and variable. The simplest case is where it opens into a vagina, which, after a short bend in any direction, opens into the central space. A more usual arrangement is for several receptaculae seminae to communicate with each other first. Of the series, the most anterior opens into a short narrow duct leading directly posteriorly and opening into what would normally be the external end of the succeeding receptaculum seminis. This again communicates by means of a similar duct with the next receptaculum seminalis, and so on until the end of the series is reached, the last receptaculum seminalis communicating only with its predecessor and its own female organs. In one special case, a receptaculum seminis was absent, the connecting duct opening directly into the ovary. About half-way along the series of short ducts connecting the whole series of receptaculae seminae (usually three or four) is another similar duct, opening at one end into the connecting ducts and at the other into the central space, fairly close to the opening of the cirrus. 

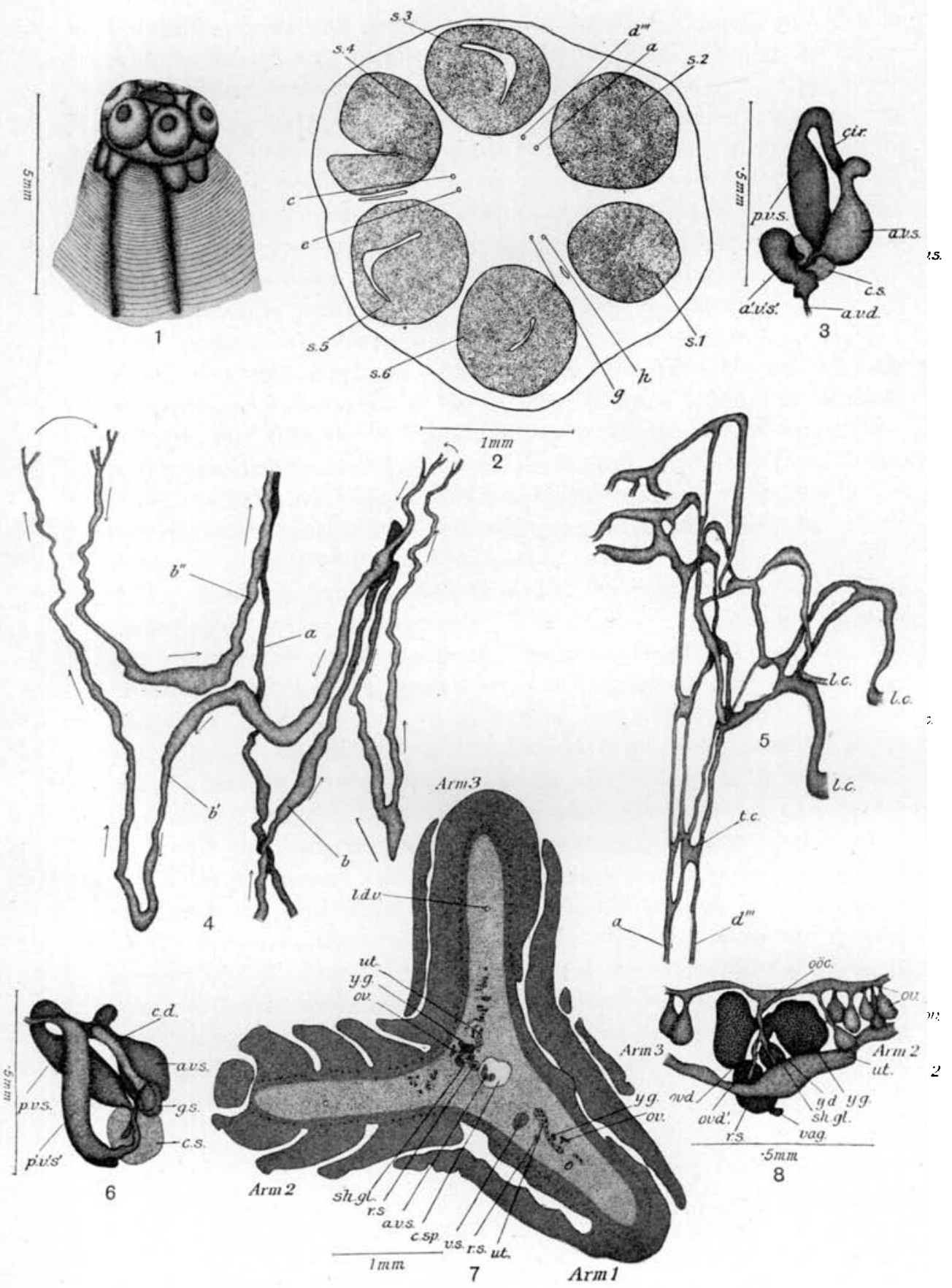


\section{REFERENCES.}

(1) Foster, W. D. (1915). Two New Cases of Polyradiate Cestodes, with a Summary of the Cases already known. Journ. of Parasit. II. 7-19.

(2) Neumann, L. G. (1890). A propos d'un Taenia trièdre de l'espèse Taenia perfoliata Goeze. Revue vétér. xv. 478.

\section{EXPLANATION OF PLATE XVIII.}

\section{REFERENCE LETTERS.}

a.v.d. anterior vas deferens; a.v.s. outer anterior vesicula seminalis; $a .^{\prime} v$.'s.' inner $^{\prime}$ anterior vesicula seminalis; c.d. common male duct; cir. cirrus; c.s. cirrus sac; $c . s p$. central space; g.s. genital sinus; l.d.v. longitudinal dorsal excretory vessel; oōc. oöclapt; ov. ovary; ovd. oviduct; p.v.s. onter posterior vesicula seminalis; $p . ' v$ 's.' $^{\prime}$ inner posterior vesicula seminalis; r.s. receptaculum seminis; $s$, sucker; sh.gl. shell-gland; $u t$. uterus; vag. vagina; $y . d$. vitelline duct; $y . g$. vitelline gland.

$a, b, b^{\prime}, b^{\prime \prime}, c, d^{\prime \prime \prime}, e, g, h, l . c .$, t.c. (for explanation see text).

Fig. 1. Scolex.

Fig. 2. Transverse section at posterior third of scolex.

Fig. 3. Male genital ducts, seen anteriorly.

Fig. 4. Excretory system in neck.

Fig. 5. Excretory system in anterior third of scolex.

Fig. 6. Male genital ducts, seen posteriorly.

Fig. 7. Transverse section of a proglottis.

Fig. 8. Female genital ducts. 